\title{
Pseudocholinesterase as a prognostic marker for liver disorder
}

\section{Dhungana $\mathrm{A}^{1}$, Sinha JN ${ }^{2}$, Sapkota $\mathrm{S}^{3}$, Singh $\mathrm{AR}^{4}$}

'Arun Dhungana, Lecturer, Department of Biochemistry, Kathmandu Medical College, Duwakot; ${ }^{2}$ Jitendra Narayan Sinha, Professor; ${ }^{3}$ Saroj Sapkota, Lecturer; ${ }^{4}$ Athokpam Rajendra Singh, Associate Professor, Department of Biochemistry, College of Medical Sciences, Bharatpur, Nepal.

\section{ABSTRACT}

Background: Liver is the main source of pseudocholinesterase. It is a non-specific cholinesterase found in the blood plasma and may be reduced in patients with advanced liver diseases. Measurement of serum pseudocholinesterase activity serves as a sensitive indicator of synthetic capacity of the liver and can be used as a prognostic marker for carcinoma. Objective: To study pseudocholinesterase activities in liver diseases.

Method: A prospective study was conducted at College of Medical Sciences Teaching Hospital (CMS-TH), from May 2011 to May 2013 with 25 controls and 25 diagnosed cases each of carcinoma of liver, cirrhosis of liver, infective hepatitis and obstructive jaundice among both sexes of same age group attending medical outpatient and inpatient departments. Serum pseudocholinesterase and other liver function tests were performed with semi-autoanalyser and Roche Hitachi 902 respectively.

Results: Pseudocholinesterase level was markedly decreased in carcinoma of liver (mean \pm SD = $1369.48 \pm 276.64$ IU/L) followed by cirrhosis of liver (mean $\pm \mathrm{SD}=1735.16 \pm 433.82 \mathrm{IU} / \mathrm{L}$ ), infective hepatitis (mean $\pm \mathrm{SD}=3800.69 \pm 764.17 \mathrm{IU} / \mathrm{L}$ ), obstructive jaundice (mean \pm SD $=5539 \pm 791.05 \mathrm{IU} / \mathrm{L}$ ) when compared with controls (mean $\pm \mathrm{SD}=6865.12 \pm 928.41$ IU/L). The difference in the means was statistically significant $(p<0.001)$.

Conclusion: There was significant decrease in pseudocholinesterase level in carcinoma of liver followed by cirrhosis of liver while less so in infective hepatitis. In obstructive jaundice the enzyme level was found to be decreased but higher than other liver diseases. The results indicated that with more severe liver cell destruction or cell degeneration, there was corresponding significant decrease in the level of pseudocholinesterase, which could be used as diagnostic marker of liver disease.

Key words: Carcinoma of liver, Cirrhosis of liver, Hepatitis, Obstructive jaundice, Pseudocholinesterase

\section{INTRODUCTION}

Deudocholinesterase (PChE) is also known - as butyrylcholinesterase (BChE), serum cholinesterase, false cholinesterase or most formally acylcholineacylhydrolase. It is found in central and peripheral nervous system, kidney, intestine, pancreas and liver (hepatocytes) ${ }^{1-3}$. It is synthesized in liver and secreted into plasma mainly as a tetrameric glycoprotein ${ }^{4,5}$. It can hydrolyse hydrophobic and hydrophilic carboxylic or phosphoric acid ester containing compounds ${ }^{6}$. It was so named due to its ability to hydrolyse butyrylcholine faster than other

Address for correspondence

Arun Dhungana

Lecturer

Department of Biochemistry

Kathmandu Medical College Teaching Hospital

E-mail address: a_dhungana1@yahoo.com esters $^{7}$. It has a half-life of about 12 days $^{1,8-11}$. Its normal value ranges between 5,900 and $13,200 \mathrm{IU} / \mathrm{L}^{12,13}$. The level of PChE measurement serve as a sensitive indicator of synthetic capacity of liver, any decrease in PChE activity reflects impaired synthesis of enzyme by the liver ${ }^{14}$. Hepatocellular impairment will reflect a decreased enzyme activity. In fact, plasma level falls in acute and chronic liver damage, cirrhosis, and liver metastases, being a biochemical marker of organ damage ${ }^{11}$. Physiologically, the function of this enzyme is unknown $n^{4,6,15,16}$. A severe fulminant liver disease can end in death before the enzyme level shows a significant fall'. A small proportion of healthy population is lacking in plasma $B C h E$, due to a genotype aberration; studies carried out in Europe indicate a three to four percent prevalence of congenital serum BChE deficiency 
subjects ${ }^{11}$. The aim of the present study was to investigate pseudocholinesterase as a probable prognostic marker in different liver disorders. This study is mainly focused on pseudocholinesterase and its activity in liver disorder.

\section{METHODS}

The present study was carried out at College of Medical Sciences Teaching Hospital, Bharatpur from May 2011 to May 2013. In the present study 25 healthy age and sex matched controls (staff and students) and 25 known cases each of carcinoma of liver, cirrhosis of liver, infective hepatitis and obstructive jaundice of both sexes between 20 to 70 years age group attending outpatient department and inpatient department were included. Serum pseudocholinesterase and other liver function tests were performed with semi-autoanalyser and Roche Hitachi 902 respectively in controls and cases. An increased activity of this enzyme has been reported in obesity, diabetes, uraemia, hyperthyroidism and hyperlipidaemic subjects ${ }^{4,12,13}$. Low plasma PChE levels have also been found in protein energy malnutrition, during stress and (chronic and acute) inflammation ${ }^{17}$. So, patients with these cases were excluded from the study.

Pseudocholinesterase estimation is done by colorimetric 5, 5'-dithiobis-2-nitrobenzoate (DTNB) method using AMP diagnostics.

\section{COLORIMETRIC METHOD}

Cholinesterase hydrolyses butyrylthiocholine to butyrate and thiocholine. Thiocholine reacts with DTNB to form nitro-2-mercapto-5-benzoate, a yellow compound according to the following reaction. It is measured at $405 \mathrm{~nm}$.
1. Butyrylthiocholine $+\mathrm{H} 2 \mathrm{O} \stackrel{\text { Cholinesterase }}{\longrightarrow}$ Butyrate + thiocholine

2. Thiocholine + DTNB $\longleftrightarrow$ nitro-2-mercapto5-benzoate

The rate of nitro-2-mercapto-5-benzoato formation, measured photometrically, is proportional to the enzymatic activity of cholinesterase in the sample.

\section{STATISTICAL ANALYSIS}

Statistical analysis was done by SPSS (Statistical package for social science) version 15 . Independent sample t-test was used to compare the means between different groups.

\section{RESULTS}

Gender and age distribution of cases and controls are shown in Table 1 and 2 . In all disease groups, there was male predominance except in obstructive jaundice. Majority of patients belonged to age group 41 to 60 years. Decrease in pseudocholinesterase level was highest in carcinoma of liver (80\%) followed by cirrhosis of liver (75\%), infective hepatitis (45\%) and obstructive jaundice (30\%) respectively as shown in Table 3.

Table 1: Gender wise distribution of control and liver disorder

\begin{tabular}{lccc}
\hline & Male & Female & Total \\
\hline Control & $13(52 \%)$ & $12(48 \%)$ & 25 \\
\hline Cirrhosis of liver & $14(56 \%)$ & $11(44 \%)$ & 25 \\
\hline Infective hepatitis & $13(52 \%)$ & $12(48 \%)$ & 25 \\
\hline Carcinoma of liver & $15(60 \%)$ & $10(40 \%)$ & 25 \\
\hline Obstructive Jaundice & $8(32 \%)$ & $17(68 \%)$ & 25 \\
\hline
\end{tabular}

Table 2: Age group distribution of control and liver disorder

\begin{tabular}{cccccc}
\hline Age group & Control & Cirrhosis of liver & Infective hepatitis & Carcinoma of liver & Obstructivejaundice \\
\hline $20-40$ & $11(44 \%)$ & $7(28 \%)$ & $13(52 \%)$ & $5(20 \%)$ & $7(28 \%)$ \\
$41-60$ & $11(44 \%)$ & $15(60 \%)$ & $9(36 \%)$ & $10(40 \%)$ & $13(52 \%)$ \\
61 and above & $3(12 \%)$ & $3(12 \%)$ & $3(12 \%)$ & $10(40 \%)$ & $5(20 \%)$ \\
\hline
\end{tabular}




\section{Table 3: Statistical analysis of data of pseudocholinesterase (values are shown in mean \pm SD)}

\begin{tabular}{|c|c|c|c|c|}
\hline Parameter & Diagnosis & Number of patients & Mean \pm S. D (IU/L) & pvalue \\
\hline \multirow{8}{*}{ PChE } & Carcinoma & \multirow{2}{*}{25} & $1369.48 \pm 276.64$ & \multirow{2}{*}{$<0.001$} \\
\hline & Control & & $6865.12 \pm 928.41$ & \\
\hline & Cirrhosis & \multirow{2}{*}{25} & $1735.16 \pm 433.82$ & \multirow{2}{*}{$<0.001$} \\
\hline & Control & & $6865.12 \pm 928.41$ & \\
\hline & Hepatitis & \multirow{2}{*}{25} & $3800.69 \pm 764.17$ & \multirow{2}{*}{$<0.001$} \\
\hline & Control & & $6865.12 \pm 928.41$ & \\
\hline & Obstructive Jaundice & \multirow{2}{*}{25} & $5539 \pm 791.05$ & \multirow{2}{*}{$<0.001$} \\
\hline & Control & & $6865.12 \pm 928.41$ & \\
\hline
\end{tabular}

$\mathrm{p}$ value calculated by independent sample t-test.

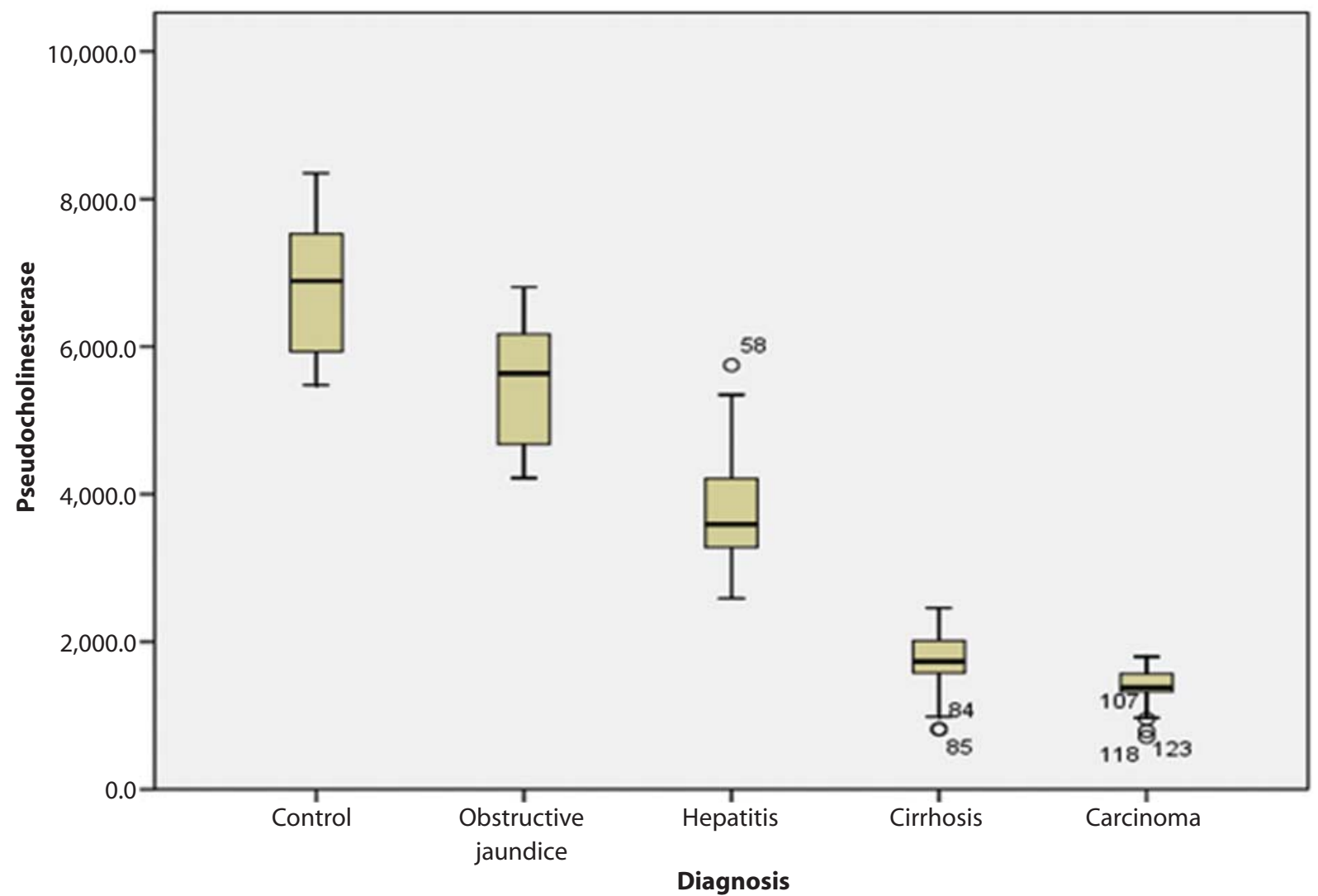

Figure 1: Box plot graph shows the mean level of pseudocholinesterase in cases of different liver diseases and control.

\section{DISCUSSION}

In the present study 25 normal controls and 100 cases suffering from hepatic diseases were included, comprising of 25 cases each of carcinoma of liver, cirrhosis of liver, infective hepatitis and obstructive jaundice. Pseudocholinesterase level was markedly decreased in carcinoma of liver (mean \pm SD $=1369.48$ $\pm 276.64 \mathrm{IU} / \mathrm{L}$ ) followed by cirrhosis of liver (mean \pm $\mathrm{SD}=1735.16 \pm 433.82 \mathrm{IU} / \mathrm{L}$ ), infective hepatitis (mean $\pm \mathrm{SD}=3800.69 \pm 764.17 \mathrm{IU} / \mathrm{L}$ ), obstructive jaundice (mean $\pm \mathrm{SD}=5539 \pm 791.05 \mathrm{IU} / \mathrm{L})$ when compared with controls (mean $\pm \mathrm{SD}=6865.12 \pm 928.41 \mathrm{IU} / \mathrm{L}$ ). The difference in the mean was statistically significant as $p<0.001$ as shown in the Table 3 . The same was shown in the Figure 1. The level of pseudocholinesterase was severely decreased in carcinoma of liver (80\%).Similar findings were also reported by Shan-Zhi Gu et al, $(2005)^{18}$, William Burnett $(1960)^{19}$ and Arun Chougule et al $(2008)^{20}$. The level of pseudocholinesterase was 
severely decreased in carcinoma of liver than infective hepatitis and cirrhosis of liver. So, one can infer therefore that, pseudocholinesterase reduces when the functional parenchymal cells are damaged or decrease, as liver synthesizes pseudocholinesterase. So, it has a survival predictive role in cancer patients and seems to correlate with disease progression. Regarding liver diseases, a decreased BChE activity reflects hepatocellular impairment; similarly, recovery was evidenced by a gradual increase of BChE levels. In advanced liver cancer with or without hepatic involvement there is mild to moderate inflammation and various degree of protein energy malnutrition resulting the level of pseudocholinesterase to decrease but in cirrhosis of liver pseudocholinesterase level would decrease very much when the number of functional parenchymal cells of liver decreases. Similarly in infective hepatitis the liver cells are damaged but hepatocytes are not decreased as compared to cirrhosis or carcinoma of liver ${ }^{18,21}$. Similar finding were also found by S Venkata Rao et al (2011) ${ }^{21}$ and also by MG Khan (1962) ${ }^{22}$.

The level of PChE $(5539 \pm 791.05$ IU/L) in obstructive jaundice was decreased as compared to control (6865.12 $\pm 928.41 \mathrm{lU} / \mathrm{L})$. The difference in the mean was statistically significant $(p<0.001)$ as shown in Figure 1. The level of pseudocholinesterase was near to normal but little less in comparison to the controls but higher than other liver disorders. Such finding was also documented by $S$ VenkataRao et al $(2011)^{21}$. Similar finding was also reported by MG Khan (1962) ${ }^{22}$. Since, in obstructive jaundice the pathogenesis lies outside the liver and it is not due to the liver cell destruction or degeneration but due to obstruction either in right and left hepatic duct or

\section{REFERENCES}

1. McQueen MJ. Clinical and analytical considerations in the utilization of cholinesterase measurements. Clin Chim Acta. 1995;237(1-2):91-105.

2. Kondo M, Hada T, Fukui K, Iwasaki A, Higashino K, Yasukawa K. Enzyme-linked immunosorbent assay (ELISA) for Aleuria aurantia lectin-reactive serum cholinesterase to differentiate liver cirrhosis and chronic hepatitis. Clin Chim Acta. 1995;243(1):1-9.

3. Oksana L. Structure of human serum cholinesterase. Bioassays. 1988;9:125-8.

4. Kutty KM, Payne RH. Serum pseudocholinesterase and very-low-density lipoprotein metabolism. J Clin Lab Anal. 1994;8(4):247-50. in gall bladder or in cystic duct or in common bile duct, the reduction is less compared to other pathologies.

A study was conducted by Ogunkeye et al (2006) ${ }^{11}$, to evaluate if serum BChE activity could help in differentiating between liver and non-liver diseases, among three groups of subjects: group 1, liver disease with at least four out of five abnormal liver function tests (aspartate transaminase (AST), alanine transaminase (ALT), alkaline phosphatase, total bilirubin, and albumin); group 2, non-liver disease with at least two abnormal liver function tests, and group 3, healthy subjects. Group 2 patients presented serum BChE activity within normal range for healthy individuals, but the mean $B C h E$ value was lower compared to the control group. However, the difference was not statistically significant. On the other hand, patients with liver diseases (group 1) had serum BChE activity well below the reference interval for healthy subjects. The predominant hepatic source of serum BChE activity, the marked decreased synthesis with hepatocyte dysfunction, and its restoration with hepatocyte recovery suggested that serum BChE activity might be a more specific marker of liver dysfunction than the more traditional liver function tests.

\section{CONCLUSION}

The results indicate that with more severe liver cell destruction or degeneration, there was significant decrease in the level of pseudocholinesterase. This study shows the important activities of pseudocholinesterase in differentiating different liver disorder. So, Serum PChE assessment should be included as a routine clinical diagnostic procedure to evaluate patient prognostic value varying from different liver disorder. So, it can be used as a prognostic biomarker.

5. La Du BN, Bartels CF, Nogueira CP, Hajra A, Lightstone $H$, Van der Spek $A$, et al. Phenotypic and molecular biological analysis of human butyrylcholinesterase variants. Clin Biochem. 1990;23(5):423-31.

6. Çoku ra AN. Butyrylcholinesterase: Structure and Physiological Importance. Turk J Biochem. 2003;28(2):54-61.

7. Manoharan I, Wieseler S, Layer PG, Lockridge O, Boopathy R. Naturally occurring mutation Leu307Pro of human butyrylcholinesterase in the Vysya community of India. Pharmacogenet Genomics. 2006;16(7):461-8.

8. Ostergaard D, Viby-Mogensen J, Hanel HK, Skovgaard LT. Half-life of plasma cholinesterase. Acta Anaesthesiol Scand. 1988;32(3):266-9. 
9. Pan Y, Muzyka JL, Zhan CG. Model of human butyrylcholinesterase tetramer by homology modeling and dynamics simulation. J Phys Chem Biol. 2009;113(18):6543-52.

10. Abdallah C, Udomtecha D. Pseudocholinesterase activity: Determination and interpretation in Pediatric anesthesia. MEJA. 2007;19(2):423-28.

11. Santarpia L, Grandone I, Contaldo F, Pasanisi F. Butyrylcholinesterase as a prognostic marker: a review of the literature. J Cachexia Sarcopenia Muscle. 2013;4(1):31-9.

12. Paes AM, Carniatto SR, Francisco FA, Brito NA, Mathias PC. Acetylcholinesterase activity changes on visceral organs of VMH lesion-induced obese rats. Int J Neurosci. 2006;116(11):1295-302.

13. Cucuianu M, Nistor T, Hancu N, Orbai $P$, Muscurel C, Stoian I. Serum cholinesterase activity correlates with serum insulin, C-peptide and free fatty acids levels in patients with type 2 diabetes. Rom J Intern Med. 2002;40(1-4):43-51.

14. Burtis CA, Ashwood ER, Bruns DE. Enzyme. In: Panteghini $M$, Bais $R$, Solinge $W$, editors. Tietz Textbook of Clinical Chemistry and Molecular Diagnostics. 4th ed. Philadelphia: Elsevier, Saunders; 2006. p. 604-16.

15. Kekwick RG. Serum-cholinesterase activity in health and in liver disease. Biochem J. 1960;76:420-4.
16. Manoharan I, Boopathy R, Darvesh S, Lockridge O. A medical health report on individuals with silent butyrylcholinesterase in the Vysya community of India. Clin Chim Acta. 2007;378(1-2):128-35.

17. Burritt MF, Anderson CF. Laboratory assessment of nutritional status. Hum Pathol. 1984;15(2):130-3.

18. Gu SZ, Zhao XH, Quan P, Li SB, Pan BR. Alterations of serum cholinesterase in patients with gastric cancer. World J Gastroenterol. 2005;11(29):4604-6.

19. Burnett W. An Assessment of the Value of Serum Cholinesterase as a Liver Function Test and in the Diagnosis of Jaundice. Gut. 1960;1(4):294-302.

20. Chougule A, Hussain S, Agarwal DP. Prognostic and diagnostic value of serum pseudocholinesterase, serum aspartate transaminase, and serum alinine transaminase in malignancies treated by radiotherapy. J Cancer Res Ther. 2008;4(1):21-5.

21. Rao SV, Kiran VSR, Indira S. A Comparative Study of Pseudocholinesterase and Liver Function Test in Cirrhosis of Liver, Infective Hepatitis and Obstructive Jaundice: A Case Control Study. JCDR. 2011;5(4):72932.

22. Khan MG. The evaluation of serum pseudocholinesterase as a liver function test. Ulster Med J. 1962;31:144-52. 